\title{
Observación del efecto reductor de N-Acetilcisteína en el metabolismo de levaduras
}

\author{
Observing reducing effect of $\mathrm{N}$-acetylcysteine in the metabolism of yeast
}

Sebastián Chapela ${ }^{1,2}$, María Milagros Romo Manzini', Hilda Burgos², Manuel Alonso ${ }^{2,3}$ y Carlos Stella².

${ }^{1}$ Hospital Británico Buenos Aires, ${ }^{2}$ Instituto de Investigaciones Biomédicas (INBIOMED) Facultad de Medicina,

${ }^{3}$ Ciclo Básico Común, Universidad de Buenos Aires. Argentina.

*e-mail: cstella@fmed.uba.ar

\section{Resumen}

La investigación se centra en el diseño de didácticas experimentales utilizando materiales de fácil adquisición y métodos sencillos de poner en práctica. Se plantea como modelo de estudio el uso de la levadura de panadería Saccharomyces cerevisiae, ya que presenta muchas de las vías metabólicas estudiadas en células superiores. En este trabajo se propuso desarrollar un ensayo que permita observar macroscópicamente la capacidad de la $\mathrm{N}$ Acetilcisteína (NAC) de estimular el poder reductor de la levadura utilizando el cambio de coloración del indicador Azul de Metileno (AM).

Palavras-chave: Estrés oxidativo; levaduras N-acetilcisteína; educación médica.

\begin{abstract}
The research focuses on the design of experimental teaching using readily available materials and simple methods to implement. It arises as an example for learning, using baker's yeast Saccharomyces cerevisiae, because it has many of the metabolic pathways existing in mammalian cells. In this paper it was developed an essay that allow students to observe macroscopically the capacity of $\mathrm{N}$ - Acetyl cysteine (NAC) to stimulate the reducing power of yeast using indicator Methylene Blue (MB) color change.
\end{abstract}

Keywords: Yeast; oxidative stress; $N$-Acetyl cysteine; medical education. 


\section{Ficha de la actividad}

\begin{tabular}{|c|c|}
\hline Título & Observación del efecto reductor de N-Acetilcisteína en el metabolismo de levaduras \\
\hline $\begin{array}{l}\text { Objetivo } \\
\text { educacional }\end{array}$ & Alumnos de las carreras de Ciencias Médicas y Biológicas \\
\hline $\begin{array}{l}\text { Disciplinas } \\
\text { relacionadas }\end{array}$ & Bioquímica, Biología. \\
\hline \multirow[t]{2}{*}{$\begin{array}{l}\text { Objetivos } \\
\text { educacionales }\end{array}$} & $\begin{array}{l}\text { Capacidad de relacionar el metabolismo con la observación macroscópica de una } \\
\text { célula. }\end{array}$ \\
\hline & $\begin{array}{l}\text { Entender el cambio de color del indicador Azul de metileno como consecuencia del } \\
\text { estado oxido reducción de coenzimas. }\end{array}$ \\
\hline $\begin{array}{l}\text { Justificación de } \\
\text { uso }\end{array}$ & $\begin{array}{l}\text { El sistema modelo de levaduras es inofensivo, práctico y accesible para el manejo } \\
\text { estudiantil. }\end{array}$ \\
\hline $\begin{array}{l}\text { Contenidos } \\
\text { trabajados }\end{array}$ & Estrés oxidativo y especies reactivas de oxígeno (ROS) \\
\hline $\begin{array}{l}\text { Duración } \\
\text { estimada }\end{array}$ & 7-10 días \\
\hline $\begin{array}{l}\text { Materiales } \\
\text { utilizados }\end{array}$ & $\begin{array}{l}\text { Levadura de panadería, glucosa, extracto de levadura, suplemento de aminoácidos y } \\
\text { vitaminas, olla a presión, azul de metileno, esferas de vidrio, placas de Petri, filtro para } \\
\text { esterilización, tubos de centrífuga clínica, tubos de ensayo y pipetas automáticas. }\end{array}$ \\
\hline
\end{tabular}




\section{Introducción}

El estrés oxidativo en un hecho común en el mundo biológico en general y lleva a efectos tóxicos dentro de la célula. En la práctica médica hay muchas enfermedades que progresan acompañadas de este estrés; tal es el caso de shock severo y séptico [1], embarazos patológicos [2] y daños por isquemia reperfusión [3,4].

Esta situación se produce por un desbalance entre la producción de especies reactivas de oxígeno (ROS) y la capacidad celular de lidiar con estas especies.

Diversos mecanismos bioquímicos, moléculas y drogas son responsables de proteger a la célula frente al estrés oxidativo. Entre los mecanismo más comunes tenemos las reacciones de detoxificación de la superóxido dismutasa (SOD), Glutatión peroxidasa (GSH-peroxidasa) y catalasa [5]. Para las drogas, entre otras, se han considerado el uso de beta-caroteno y Vitamina $\mathrm{E}$ [6].

En general, estos temas son enseñados a nivel teórico en cursos universitarios de Biología Celular o Bioquímica. Sin embargo, consideramos que sería provechoso para los estudiantes abordar en forma experimental el aprendizaje de este tema utilizando el sistema modelo levadura $[7,8]$.

Nos planteamos, por tanto, el desarrollo de un ensayo que se pueda realizar fácilmente en una clase de trabajos prácticos o a modo de mostración. El ensayo permite observar macroscópicamente [9] las propiedades de una molécula antioxidante como la $\mathrm{N}$-Acetilcisteína $[10,11]$ para establecer un medio intracelular reductor, usando como indicador la coloración del Azul de Metileno [12] (AM).

\section{Materiales y métodos}

\subsection{Células}

En todos los ensayos se utilizaron levaduras de panadería (Levex®). Estos microorganismos son inocuos y pueden manipularse por alumnos inexpertos. Se extrajo una pequeña porción del paquete, se colocó en $10 \mathrm{ml}$ de agua destilada estéril y se sembró en medio sólido para aislar colonias. Estas colonias son la fuente de inoculo de todos los experimentos, ya que aseguran la ausencia de contaminación $[13,14]$.

\subsection{Medio de Cultivo}

Se utilizó medio YPD, (Extracto de Levadura $1 \%$, Peptona $1 \%$, Glucosa $2 \% \mathrm{p} / \mathrm{v}$ ) y agar $2 \% \mathrm{p} / \mathrm{v}$. Todos los componentes de este medio son de Difco pero pueden ser 
reemplazados por otros de menor costo como azúcar de mesa, $2 \% \mathrm{p} / \mathrm{v}$; caldo de carne filtrado $10 \% \mathrm{p} / \mathrm{v}$, levadura de cerveza en polvo, suplementos nutricionales de aminoácidos, etc $[13,14]$. El agar puede ser reemplazado por el ofrecido en comercios de productos dietéticos utilizando la misma concentración.

\subsection{Reactivos}

La N-Acetilcisteína (NAC) de uso humano se obtuvo de los comprimidos Acemuk 600 del laboratorio IVESTI. Los comprimidos son de uso oral con acción mucolítica de las vías respiratorias. La solución madre se obtuvo disolviendo un comprimido conteniendo $600 \mathrm{mg}$ de NAC en $40 \mathrm{ml}$ de agua destilada.

La solución se esterilizó por filtración. $450 \mu \mathrm{l}$ o $900 \mu \mathrm{l}$ de esta solución se usaron para suplementar $13 \mathrm{ml}$ de top agar conteniendo $200 \mu \mathrm{l}$ de una solución $0,1 \%$ de Azul de Metileno (AM)

\subsection{Top agar}

Se preparó con agar (Difco) al $1 \%$ en agua, se esterilizó y antes de verter sobre el cultivo se dejó entibiar.

\subsection{Inoculación de placas}

Placas de medio sólido YPD se inocularon con células de levadura con la técnica de inoculación con esfera de vidrio [13]. Básicamente se agrega a la placa una alícuota de 100-200 $\mu \mathrm{l}$ de una suspensión diluida de levaduras y la siembra se completa haciendo recorrer la esfera por la superficie de la placa.

Las colonias se cubren con Top agar con/sin el suplemento de AM. Al cabo de 7-10 días a $30^{\circ} \mathrm{C}$ o temperatura ambiente puede observarse la diferente coloración de las colonias.

\subsection{Esterilización}

El medio de cultivo y todos los elementos utilizados para manipular las células fueron esterilizados por calor húmedo en una olla a presión durante 30 min.

\subsection{Procedimientos didácticos}

La clase está organizada en dos partes. En la primera parte el docente explica el fundamento del trabajo y se procede a sembrar las placas. Puede ser individual o en 
grupos, dependiendo del número de alumnos. El docente puede disponer de tubos adicionales con top agar para que los alumnos practiquen la cobertura que sigue a la siembra. Puede aprovecharse el momento para que los alumnos deliberen sobre temas como esterilidad, nutrientes, dilución de células y difusión del oxígeno.

Sería interesante que cada alumno redactara en su cuaderno cuáles son sus expectativas respecto del resultado a obtener luego de incubar las placas.

En la segunda parte el docente recapitula el ensayo y los alumnos recibirán las placas sembradas y con crecimiento celular. Se discutirá sobre la base de relacionar la observación macroscópica con el metabolismo de la célula.

El docente debe aclarar que se ha usado un sistema modelo en particular, pero que pueden usarse otros sistemas. No es un "trabajo práctico de levaduras" sino de metabolismo y estrés oxidativo.

\section{Resultados y discusión}

Nuestro abordaje experimental, utilizando y estudiando procesos biológicos en células vivas, complementa las formas tradicionales de enseñanza que, en muchos casos, resultan demasiado abstractas y por tanto, de difícil comprensión.

El ensayo permite que los alumnos predigan y comprueben fácilmente los resultados de un experimento dentro de un contexto de enseñanza particular. De esta forma, se consigue una mayor aproximación a la relación entre la teoría y el concepto biológico que se pretende enseñar.

Este instrumento didáctico les muestra a los estudiantes evidencias macroscópicas de aspectos microscópicos de los temas propuestos.

Alumnos del tercer año de la carrera de Ciencias Médicas inocularon placas con una suspensión de células y la dispersaron con una esfera de vidrio estéril. Debido a que el top agar contiene $1 \%$ de agar, su distribución no ofreció inconvenientes. Los eventuales problemas pueden derivarse de la cubrir con el top agar en forma incompleta la superficie sembrada de la placa.

Este inconveniente se evita disponiendo de algunos tubos de reserva para que el alumno practique previamente el volcado del top agar. En todos los ensayos se observó crecimiento de colonias.

Es importante que el docente elija levaduras de panadería de uso habitual. De esta manera se asegura que las levaduras crezcan luego de ser inoculadas por los alumnos. No hemos observado contaminación en las placas y es aconsejable realizar todas las 
operaciones en un ambiente libre de corrientes de aire.

Diversos mecanismos bioquímicos son responsables de moderar el estrés oxidativo dentro de una célula. Sin embargo el amplio uso o "polisemia social" de la palabra estrés hace que su significado se diluya a la hora de enfocar el tema de las especies reactivas de oxígeno (ROS). A través de este simple ensayo el alumno puede "ver" que un color, en este caso el azul representa una situación de estrés y la falta de color a una situación de balance redox dentro de la célula. La Figura 1 presenta los resultados obtenidos.

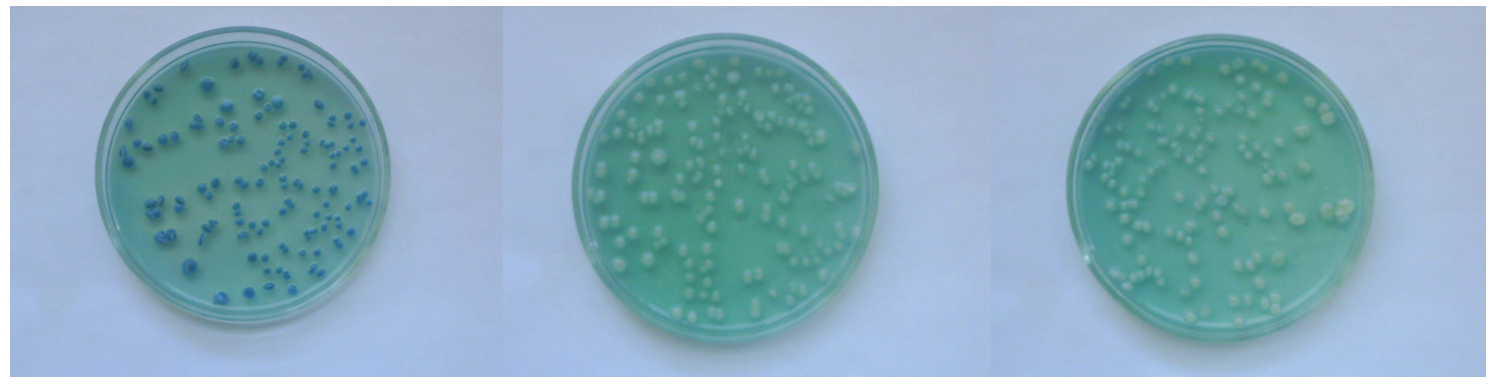

A

B

C

Figura 1. (A) Células con top agar control (B) top agar con $450 \mu \mathrm{l}$ de solución de NAC y (C) top agar con $900 \mu \mathrm{l}$ de solución de NAC.

La reacción para el colorante se puede resumir:

$$
\mathrm{AM}+2 \mathrm{H}^{+}+2 \mathrm{e} \quad \rightarrow \quad \mathrm{AMH}_{2}
$$

(oxidado/azul)

(reducido/incoloro)

En la placa A las colonias presentan una coloración azul mientras que el agregado de NAC en el top agar (B, C) cambia el color de azul a incoloro indicando un cambio en el estado de oxidación del colorante. El metabolismo de la célula ha reaccionado con el AM en forma análoga a la reacción con la coenzima oxidada NAD ${ }^{+}$cuando se genera NADH + $\mathrm{H}^{+}$.

Si bien el $\mathrm{AM}$ ha sido utilizado en otros protocolos de enseñanza, en dichos ensayos se hace hincapié en su acción como cofactor de la enzima succinato deshidrogenasa [15]. En el caso de Anuradh G. y col. han diseñado un dispositivo con el colorante y la levadura para obtener energía eléctrica [16]. Nuestro trabajo extiende el uso del colorante para captar el cambio de estado redox de la célula.

El docente debe hacer hincapié en que el color responde a una situación metabólica y podría haberse usado otro colorante de diferente coloración. Esto lo 
mencionamos sobre la base de nuestra experiencia con estudiantes de medicina al usar kits de glucosa. Los estudiantes a veces asocian el color rosado con la molécula de glucosa sin considerar que la coloración simplemente pone de manifiesto una situación metabólica independientemente del colorante usado. Podrá aprovecharse la clase para mencionar las aplicaciones clínicas de técnicas que involucran al AM. En la terapia fotodinámica [17] células conteniendo AM son irradiadas con luz roja (600-650 nm) exacerbando la capacidad del colorante de producir ROS en las células en que se concentró.

Usualmente, este contenido se trata en las clases en algún hueco entre distintos temas y eso hace que al alumno no comprenda que la producción de ROS sobreviene continuamente de la misma forma que la célula mantiene una homeostasis de combustibles como la glucosa.

Esta didáctica experimental resulta apropiada para trabajar con alumnos inexpertos sin correr riesgos, dada la inocuidad de estas levaduras. Al mismo tiempo, presenta resultados muy claros para su observación macroscópica e interpretación directa sin necesidad de contar con elementos costosos o de difícil manipulación.

\subsection{Impacto en la enseñanza}

En ensayos previos hemos notado que el mayor impacto es en la motivación. Durante el ensayo los alumnos hacen más preguntas que en las clases teóricas. Su papel es más activo. Preguntan por la esterilización, nutrientes, el uso de guantes y en pocos casos se olvidan de traer su delantal de laboratorio. El alumno al ver las placas con crecimiento suele decir "iguau, esto lo hice yo!". Esta motivación facilita la tarea del docente para construir conocimiento.

A partir del ensayo el docente puede hilvanar otros temas ya vistos durante el curso. Por ejemplo se puede discutir el papel de cada nutriente en el crecimiento celular.

El medio de cultivo tiene fuentes de nitrógeno, carbono, vitaminas e iones que pueden relacionarse con las vías metabólicas a estudiarse en el curso (glucólisis, ciclo de los ácidos tricarboxílicos, etc)

Otro impacto es que el alumno "ve" la relación entre su observación personal y lo que el docente le mostró sobre un pizarrón. Se podrá discutir la importancia de los experimentos en Bioquímica para deducir conclusiones sobre el funcionamiento celular. 


\section{Consideraciones finales}

Se exhibe un ensayo con el sistema modelo de levaduras, que representa una célula eucariota capaz de crecer en forma individual. El colorante AM difunde al interior de la célula y su cambio de color permite visualizar el estado de óxido reducción de la célula y el efecto de la droga N-Acetilcisteína.

El ensayo es simple y permite discutir el crecimiento de una célula y el efecto de una droga sobre el metabolismo. Si bien existen videos o animaciones sobre el metabolismo celular, nada reemplaza el ensayo concreto sobre la mesada de un laboratorio.

Durante la realización de un ensayo experimental surgen consultas o problemas que no pueden contemplarse con otras herramientas para la enseñanza. Este protocolo puede articularse junto a otras herramientas sin que su preparación altere o demande grandes cambios dentro de la organización de la enseñanza.

\section{Referencias}

[1] Martins PS, Kallas EG, Neto MC, Dalboni MA, Blecher S, Salomão R. Upregulation of reactive oxygen species generation and phagocytosis, and increased apoptosis in human neutrophils during severe sepsis and septic shock. Shock 2003;20:208-212.

[2] Hung TH, Skepper JN, Burton GJ. In vitro ischemia-reperfusion injury in term human placenta as a model for oxidative stress in pathological pregnancies. Am J Pathol 2001;159:1031-1043.

[3] Wischmeyer PE, Vanden Hoek TL, Li C, Shao Z, Ren H, Riehm J, Becker LB. Glutamine preserves cardiomyocyte viability and enhances recovery of contractile function after ischemia-reperfusion injury. JPEN J Parenter Enteral Nutr 2003;27:116-122.

[4] Lièvre V, Becuwe $P$, Bianchi A, Koziel V, Franck P, Schroeder H, Nabet P, Dauça M, Daval JL. Free radical production and changes in superoxide dismutases associated with hypoxia/reoxygenation-induced apoptosis of embryonic rat forebrain neurons in culture. Free Radic Biol Med 2000;29:1291-1301.

[5] Blanco A, Química Biológica, Argentina: Editorial El Ateneo, Sexta Edición; 1993, pág. 177.

[6 ] Tabei SMB, Fakher S, Djalali M, Javanbakht MH, Zarei M, Derakhshanian H, Sadeghi MR, Mostafavi E, Kargar F. Effect of vitamins A, E, C and omega-3 fatty acids supplementation on the level of catalase and superoxide dismutase activities in streptozotocin-induced diabetic rats Bratisl Lek Listy 2015; 116 (2) 115118

[7] Żyracka E, Zadrąg R, Kozioł S, Krzepiłko A, Bartosz G, Tomasz B. Yeast as a biosensor for antioxidants: simple growth tests employing a Saccharomyces cerevisiae mutant defective in superoxide dismutase. Acta Biochimica Polonica. 2005; 3 (52): 679-684

[8] Mirek K, Zadrag-Tecza R, Bartosz G. Ascorbate and thiol antioxidants abolish sensitivity of yeast Saccharomyces cerevisiae to disulfiram Magdalena. Cell Biol Toxicol 2012; 28:1-9

[9] Alonso, M., Stella, C.A., Monti Hughes, A., Garófalo, J. and Galagovsky, L. Modelo experimental para el aprendizaje de la función de la digestión química extracelular de los alimentos. IV Jornadas Internacionales para la Enseñanza Preuniversitaria y Universitaria de la Química. Mérida, Yucatán, México. 2005.

[10] Zafarullah, M., Li, W.Q., Sylvester, J. and Ahmad, M. (2003) Molecular mechanisms of N-acetylcysteine actions. Cell. Mol. Life Sci. 60, 6-20.

[11] Guaragnella N, Passarella S, Marra E, Giannattasio S. Knock-out of metacaspase and/or cytochrome c results in the activation of a ROS-independent acetic acid-induced programmed cell death pathway in yeast 
FEBS Letters 584 2010; 3655-3660

[12] The Merck index,. USA: Merck Research Laboratories Division of Merck \& Co., Inc. Thirteenth edition Whitehouse Station, NJ 2001; page 6085

[13] Monti-Hughes, A., Alonso, M.., Garófalo, J., Burgos, H.I., and Stella, C.A. Teaching about Lactose Metabolism: a complex challenge faced with a simple kit.Biochemistry and Molecular Biology Education. 2007; (35): 359-363.

[14] Alonso M, Stella CA. Teaching nutritional biochemistry: an experimental approach using yeast. Adv Physiol Educ. 2012; 36 (4):313-8.

[15] Lehninger A.L.Biochemistry. Worth Publishing Inc. N.Y. 1975; p. 446-447

[16] Anuradh G., Sandun F., Filip T. Performance of a Yeast-mediated Biological Fuel Cell. Int. J. Mol. Sci. 2008, 9, 1893-1907

[17] Kharkwal GB, Sharma SK, Huang Y, Dai T, Hamblin MR.. Photodynamic Therapy for Infections: Clinical Applications, Lasers Surg Med. 2011; 43(7): 755-767 